J. Biosoc. Sci., (2017) 49, 648-663 C Cambridge University Press, 2016. This is an Open Access article, distributed under the terms of the Creative Commons Attribution licence (http:// creativecommons. org/licenses/by/4.0/), which permits unrestricted re-use, distribution, and reproduction in any medium, provided the original work is properly cited.

doi:10.1017/S0021932016000560 First published online 28 Nov 2016

\title{
USE OF MALE METHODS OF CONTRACEPTION WORLDWIDE
}

\author{
JOHN ROSS ${ }^{* 1}$ AND KAREN HARDEE $\uparrow$ \\ *Independent Demographic Consultant, New Paltz, New York, USA and †The \\ Evidence Project, Population Council, New York, USA
}

\begin{abstract}
Summary. This article analyses male contraceptive use, both globally and for developing countries. Shares of all contraceptive use due to males are examined, in the context of female use and all use. Patterns according to wealth quintiles are analysed, as well as time trends and geographic variations. Data are drawn primarily from compilations by the UN Population Division and from the Demographic and Health Series and subjected to relatively simple statistical methods including correlation/regression applications. Contraceptive methods that men use directly, or that require their co-operation to use, including condoms, withdrawal, rhythm and male sterilization, account for one-quarter of all contraceptive use worldwide. This represents $13 \%$ of married/in-union women. Both the share and the prevalence of male methods vary widely by geography and by the four methods, as well as by quintile wealth groups. With greater wealth there is an unbroken rise for total use; among the male methods, the shares of condom use and rhythm rise by wealth quintiles, while the share of withdrawal drops. The share for male sterilization is highest in the lowest and highest wealth quintiles and dips for the middle quintiles. The overall time trend since the 1980s has been steady at one-quarter of all use involving men; moreover, the share is about the same at all levels of total use. The female-only methods continue to dominate: female sterilization, IUD, pill, injectable and implant, again with great diversity geographically. In surveys men report less total use but more condom use, while females report more injectable use. For the future the male share of one-quarter of use seems secure, with little prospect of an increase unless concerted programmatic efforts are made to expand access to male methods and promote their use as part of a broadened contraceptive method mix.
\end{abstract}

\section{Introduction}

Organized family planning programming in the developing world since the 1960s has primarily focused on women, with less attention to involving men. Efforts for an

${ }^{1}$ Corresponding author. Email: RossHome8@Frontiernet.net 
improved gender balance grew as a result of the 1994 International Conference on Population and Development (ICPD), but since then the need has persisted to reinforce male involvement and engage them as users of family planning as well as supportive partners for its use by women (IGWG, 2009).

Inattention to men has been accompanied by a dearth of publications examining their role. Few empirical studies have clarified the extent of their contraceptive use and the ways in which it has varied along geographic lines and personal characteristics. The most comprehensive treatment of men and family planning was produced three decades ago (Gallen et al., 1986). Since then a briefer analysis was undertaken by HardeeCleaveland (1992). These analyses found that use of male methods or methods that required their co-operation, namely condoms, withdrawal, rhythm and male sterilization, accounted for one-quarter of all contraceptive method use worldwide. Recently MacQuarrie et al. (2015) undertook an analysis of male-only surveys from eighteen countries, covering a range of attitudinal and behavioural measures.

The broader picture of contraceptive use for all methods, with attention to distorted patterns that favour either a single method or a few methods, has been presented by Ross et al. (2015), Seiber et al. (2007) and Sullivan et al. (2006). The diversity among countries and methods is remarkable, within the overriding tendency for a few methods to account for most use.

If family planning programmes are to increase their focus on men as contraceptive users and as enablers of their female partners' use, they will do so more effectively with a clearer picture of current male behaviour worldwide, regionally and nationally. This article attempts to inform that effort by examining global patterns and trends for male contraception from the available sources, in relation to total contraceptive use and to wealth quintiles. This analysis is a companion to a forthcoming assessment of programming for men as family planning users (Hardee et al., 2016).

\section{Methods}

\section{Data sources}

The analysis uses two primary data sources. The first data series comes from the UN Population Division, based on 1059 national surveys in 195 countries/areas (UN Population Division, 2015a, b and c). Prevalence of use by contraceptive method is given for 1994, 2015 and 2030. All data are for married/in-union women aged 15-49, to have common base across numerous national surveys. To create the prevalence estimates, the UN subjected the full set of surveys for each country to a hierarchical model that used the country-specific time trends (Alkema et al. 2013).

To establish method mixes for 2015, the UN used the latest surveys since 2000 from 163 counties/areas. Separately, to establish method mixes for 1994, the most recent surveys in the period 1985 to 1999 from 159 countries/areas for which data were available were used. Regional estimates were weighted, using the number of married/in-union women aged 15-49 in each country/area in 1994 and 2015. Most analyses below use the 2015 estimates; the 1994 estimates are used only to look at time trends.

The contraceptive methods considered in this paper are the same as those in the UN series. These include four methods that men use, or that require their co-operation, 
and five female methods. For males these are sterilization, condom, withdrawal and rhythm. They differ in character: sterilization requires a male-only action, while condom use requires an explicit male action but is subject to negotiation between the partners since either may favour or disfavour condom use. Withdrawal requires an explicit male action but it terminates coitus and the female partner may or may not encourage its use. Rhythm requires male co-operation. It is included with male methods primarily to gauge the role of males in overall contraceptive use. Note that the Standard Days Method (SDM), a modern method of contraception, which also requires male co-operation, would have been included in the analysis, but its use does not yet register in many surveys, as noted below. In this paper, the four methods that require direct action or co-operation by men to use are referred to as male methods.

Female methods include sterilization, IUD, pill, injectable and implant. None require male involvement in the way that the rhythm method (or SDM) does. 'Other' methods are included in the data sets, but they occur usually in tiny percentages, and are omitted from the presentations here. The SDM is not shown separately as it is unavailable in the UN series, and in the StatCompiler for DHS only nine of 248 surveys show non-zero values for the percentage of married/in-union women using the method, and the range is only from $0.6 \%$ to $0.1 \%$.

A second data set comes from the Demographic and Health Survey (DHS) series, accessed in the StatCompiler (ICF International, 2015), which for contraceptive data includes as many as 248 surveys in up to 83 countries, although for some variables in this analysis fewer surveys were available. 'DHS' serves as a generic term since the series includes also the CPS (Contraceptive Prevalence Surveys) and RHS (Reproductive Health Surveys). As with the UN series, attention is primarily on married/in-union women in these surveys.

A limitation of this analysis is that these data omit behaviour by single and unmarried men who are not partners of married/in-union women, as well as behaviour by sexually active single women and their partners, which in some countries show more contraceptive use than by married women. Furthermore, the data come from responses from women rather than men. Far fewer national surveys include men, but one section below compares responses between men and women within the same household, and another section summarizes findings from male-only surveys covering all marital statuses.

The different data sets add important evidence to the analysis. The UN series includes more countries, and gives estimates for them at the same, current date of 2015. The DHS series includes fewer countries, but has more data points across multiple surveys in many of them, and offers more variables in more detail. A third data source, from male-only surveys (MacQuarrie et al., 2015), is useful to explore briefly information from males of all marital statuses.

\section{Comparisons of the two data sources}

The UN and DHS data sets do not agree entirely, and they are used for different purposes in the analyses below. A comparison of them for the total CPR and for the sum of male methods shows that the differences are due to understandable reasons. Generally the UN's 2015 estimates run higher than in the latest survey for the CPR and for some of the male totals, since the greater the interval since the latest survey the greater the chance of the projection being higher. In fact, the large differences usually appear just with the 
older DHS surveys. Sometimes the 2015 figure is below that of the latest survey, when the overall time trend in the Bayesian projection points to a lower 2015 level. (Because the regional averages are unweighted means, the 43 African surveys strongly affect the results; for example, the total Contractive Prevalence Rate (CPR) is only $46.3 \%$ and $39.9 \%$ by the two estimates.)

\section{Results}

\section{Contraceptive prevalence and method mix, by region}

Because a key question for male contraceptive use is its role within the context of the other methods, Fig. 1a displays the global picture for the prevalence of each method, shown for all major regions of the world, for both developed and developing countries. Globally, prevalence of male methods reaches $15.7 \%$ of married/in-union women for 2015 (see the bottom four methods in the first bar). Prevalence ranges by region from a low of $5.7 \%$ in Africa to highs of $29.3 \%$ and $30.2 \%$ in Northern America and Europe respectively. Prevalence levels at $15.4 \%$ in Asia and $17.6 \%$ in Latin America are close to the global average.

The condom is the most used male method globally, at $7.7 \%$, followed by withdrawal at $3.1 \%$, rhythm at $2.6 \%$ and male sterilization at $2.4 \%$, and this varied considerably by region. Figure $1 \mathrm{~b}$ converts Fig. 1a to the method mix. In each bar the four male methods are at the bottom to better show their totals. Among the male methods, condoms appear first as the most used method overall, with a share of $12.3 \%$ of all contraceptive use worldwide. The low figures are 6.7\% in Africa and 6.0\% in the least developed countries, 35 of which are in sub-Saharan Africa, along with eight in Asia, four in Oceania and one in Latin America. The highest share of condom use is in Europe, at 24.6\%.

The other three methods have smaller shares of total use. Globally, withdrawal has a 4.9\% share, being lowest in Africa and highest in Europe. Rhythm's share globally is $4.2 \%$, but it is well above that in Africa and in the least developed countries. The reverse is the case for male sterilization; it is nearly absent in Africa and in the least developed countries.

\section{Aggregation of the four male methods}

Within regions, there is a great disparity in the total of male method use, as shown in Table 1. The male share of all use ranges within Africa from a mere $8.0 \%$ in Northern Africa to $67.5 \%$ in Middle Africa, i.e. over two-thirds of use. In Asia the range is from $12.0 \%$ to $44.0 \%$, and in Europe from $18.9 \%$ to $60.0 \%$. Among the eight largest developing countries, male methods show a low share in Indonesia at $8.7 \%$, spread across condoms, withdrawal and rhythm, and a high share in Pakistan at $50.4 \%$ due to condom use and withdrawal. Table 1 also shows prevalence for each male method within regions. The condom leads among the male methods for the world at large, and in most sub-regions. It is used by $21-24 \%$ of married women/couples in two parts of Europe and by about $10 \%$ in Latin America, Northern America and Oceana. Regarding sterilization, high figures appear in Northern Europe, Northern America and Australia/New Zealand. Among the largest eight countries, China and Brazil lead, and they control the East Asia and South America averages for male sterilization.

Withdrawal and rhythm compete; overall withdrawal has the edge, but the ratio between them is much different from region to region. In Africa rhythm is more 


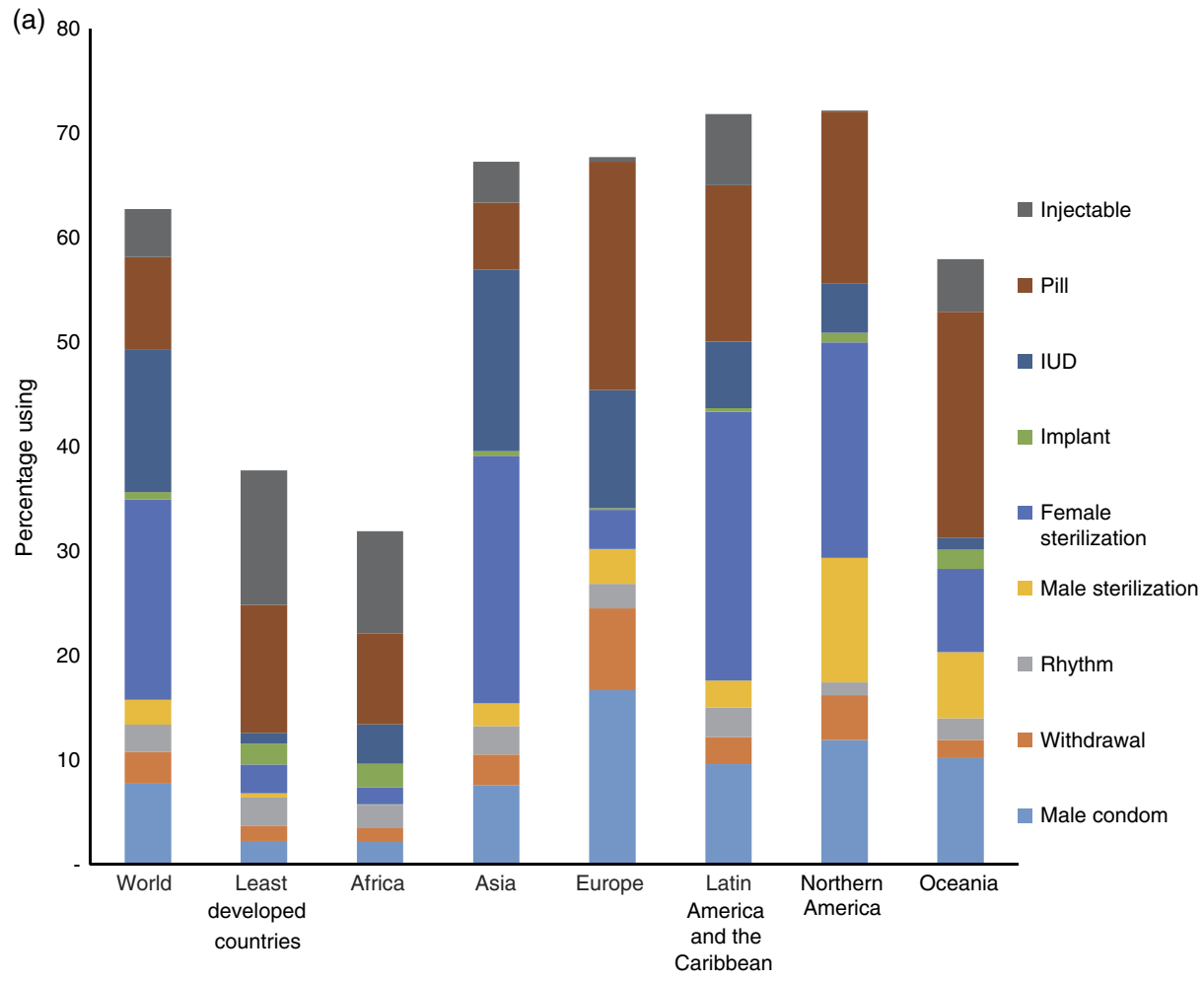

(b)

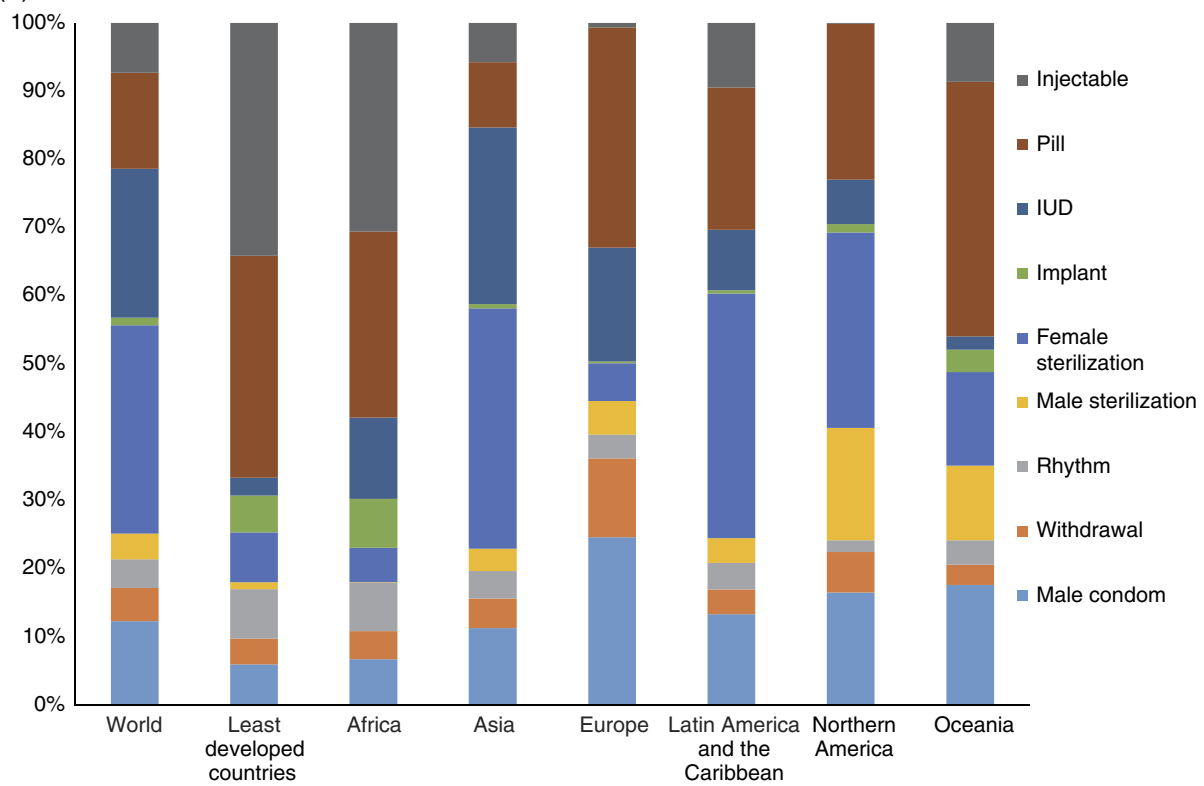

Fig. 1. Contraceptive prevalence (a) and methods mix (b) for married or in-union women aged 15-49, by method and region, 2015. 
Table 1. Share of all use due to male methods, and prevalence of each method, by region

\begin{tabular}{|c|c|c|c|c|c|c|}
\hline \multirow[b]{2}{*}{ Region } & \multirow{2}{*}{$\begin{array}{c}\text { Share }(\%) \\
\begin{array}{l}\text { Share of total } \\
\text { use due to four } \\
\text { male methods }\end{array}\end{array}$} & \multicolumn{5}{|c|}{ Prevalence } \\
\hline & & $\begin{array}{c}\text { Male } \\
\text { sterilization }\end{array}$ & $\begin{array}{l}\text { Male } \\
\text { condom }\end{array}$ & $\begin{array}{l}\text { With- } \\
\text { drawal }\end{array}$ & Rhythm & Total \\
\hline World & 24.8 & 2.4 & 7.7 & 3.1 & 2.6 & 15.7 \\
\hline Least developed countries & 17.2 & 0.4 & 2.2 & 1.4 & 2.7 & 6.8 \\
\hline Africa & 17.2 & 0.0 & 2.1 & 1.3 & 2.2 & 5.7 \\
\hline Sub-Saharan Africa & 20.8 & 0.0 & 2.4 & 1.3 & 2.2 & 5.9 \\
\hline Eastern Africa & 9.9 & 0.0 & 1.7 & 0.8 & 1.4 & 3.9 \\
\hline Middle Africa & 67.5 & 0.1 & 5.0 & 3.1 & 7.0 & 15.3 \\
\hline Northern Africa & 8.0 & 0.0 & 0.8 & 1.3 & 2.1 & 4.2 \\
\hline Southern Africa & 13.7 & 0.7 & 7.4 & 0.4 & 0.3 & 8.8 \\
\hline Western Africa & 28.2 & 0.0 & 1.8 & 1.3 & 1.6 & 4.7 \\
\hline Asia & 22.7 & 2.2 & 7.6 & 2.9 & 2.7 & 15.4 \\
\hline Eastern Asia & 19.8 & 4.4 & 10.4 & 0.6 & 0.8 & 16.2 \\
\hline Central Asia & 12.0 & 0.0 & 4.0 & 1.5 & 1.3 & 6.8 \\
\hline Southern Asia & 26.5 & 1.2 & 6.4 & 3.5 & 4.4 & 15.5 \\
\hline South-Eastern Asia & 17.4 & 0.3 & 4.0 & 3.7 & 3.3 & 11.2 \\
\hline Western Asia & 44.0 & 0.0 & 8.6 & 15.1 & 2.0 & 25.7 \\
\hline Europe & 43.6 & 3.3 & 16.7 & 7.8 & 2.4 & 30.2 \\
\hline Eastern Europe & 56.0 & 0.0 & 24.1 & 11.8 & 2.5 & 38.5 \\
\hline Northern Europe & 37.2 & 16.4 & 8.8 & 1.9 & 1.4 & 28.6 \\
\hline Southern Europe & 60.0 & 4.1 & 20.6 & 12.9 & 1.4 & 39.1 \\
\hline Western Europe & 18.9 & 2.7 & 7.4 & 0.6 & 2.6 & 13.2 \\
\hline $\begin{array}{l}\text { Latin America and the } \\
\text { Caribbean }\end{array}$ & 24.2 & 2.6 & 9.6 & 2.6 & 2.8 & 17.6 \\
\hline Caribbean & 20.3 & 0.5 & 9.3 & 1.3 & 1.6 & 12.7 \\
\hline Central America & 18.0 & 1.9 & 6.1 & 2.3 & 2.5 & 12.8 \\
\hline South America & 27.4 & 3.2 & 11.3 & 2.9 & 3.1 & 20.4 \\
\hline Northern America & 39.2 & 11.9 & 11.9 & 4.3 & 1.2 & 29.3 \\
\hline Oceania & 34.2 & 6.3 & 10.2 & 1.7 & 2.1 & 20.3 \\
\hline Australia/New Zealand & 38.0 & 9.0 & 14.1 & 1.8 & 1.3 & 26.1 \\
\hline $\begin{array}{l}\text { Melanesia, Micronesia } \\
\text { and Polynesia }\end{array}$ & 20.6 & 0.6 & 1.8 & 1.8 & 3.8 & 7.9 \\
\hline \multicolumn{7}{|l|}{$\begin{array}{l}\text { Eight largest developing } \\
\text { countries }\end{array}$} \\
\hline China & 16.4 & 4.4 & 8.3 & 0.5 & 0.5 & 13.7 \\
\hline India & 24.5 & 1.2 & 6.0 & 2.3 & 5.1 & 14.6 \\
\hline Indonesia & 8.7 & 0.2 & 1.8 & 2.2 & 1.2 & 5.5 \\
\hline Bangladesh & 16.6 & 0.6 & 4.0 & 0.9 & 5.2 & 10.7 \\
\hline Pakistan & 50.4 & 0.3 & 9.9 & 8.4 & 0.8 & 19.4 \\
\hline Brazil & 26.1 & 5.0 & 11.9 & 2.5 & 1.3 & 20.6 \\
\hline Nigeria & 41.9 & 0.0 & 2.5 & 2.2 & 2.0 & 6.7 \\
\hline Mexico & 17.6 & 2.2 & 6.5 & 2.0 & 2.1 & 12.8 \\
\hline
\end{tabular}


important, with implications for SDM in that region, but the reverse holds in Europe, and Western Asia much prefers withdrawal. Among the eight largest countries the ranking of the two methods is mixed.

In Table 1, the population-weighted average globally shows $15.7 \%$ of all married women/couples using male methods. Most countries lie in a fairly smooth distribution with the total ranging up to about $30 \%$, though twelve countries lie above that, up to $55 \%$. These twelve fall into nearly every region, with no consistent pattern.

Figure 2 illustrates for regions and sub-regions the levels of contraceptive use for male vs female methods, with rhythm separated from the other three male methods to recognize its more collaborative character. Female methods clearly dominate in every sub-region except in Middle Africa and in two of the four Europe sub-regions. The three male methods represent about half of all use in Eastern Europe and Southern Europe, where total use is also substantial. Male methods are also significant in Western Asia. In Middle Africa, when rhythm is added to the other male methods, the combination accounts for over two-thirds of all use, as noted above. However the four male methods, on average, play a small role in contraceptive use in the group of 48 least developed countries. Male use is low there; the exception in the entire developing world is Middle Africa. Among the eight largest developing countries the absolute levels for male use are far below those for female use, except in Pakistan. Nigeria shows the least total use for both male and female methods.

\section{Trends for prevalence of each male method: 1994 to 2015}

Because the UN produced estimates for 1994 in addition to 2015, it is possible to get a reasonable picture of the 21-year trend in contraceptive use. Figure 3 shows, for prevalence, the change for each male method and for the sum. This figure pertains only to the 106 developing countries with estimates for both years, not to the global total. Therefore, total male prevalence here is only $13.6 \%$, as distinct from the global figure of $15.7 \%$ cited above. Figure 3 shows that over the 21 years all use rose by 2.9 points for male methods (10.7\% to $13.6 \%)$. While the straight lines in Fig. 3 no doubt conceal numerous fluctuations during the entire period, they nevertheless show the net change in the prevalence of male methods.

Use of the four male methods was more balanced in 1994, ranging from $2.1 \%$ to $3.7 \%$ across the methods. Over the two decades to 2015 condom use rose significantly, to $6.3 \%$ on average across the developing countries. Meanwhile, use of rhythm remained steady at $2.7 \%$, and withdrawal grew slightly from $2.2 \%$ to $2.7 \%$. Male sterilization lost ground, falling from $3.7 \%$ to only $1.9 \%$.

\section{Relation of male shares to the overall prevalence level}

As countries experience the historic transition in contraceptive use from minimal levels to higher ones, what happens to the male share? Modern methods are largely unknown at the start, so the traditional methods of withdrawal and rhythm, plus some condom use, might account for most use. Also, apart from the male share, do absolute gains in male and female use move up together? That is explored in three ways below, 


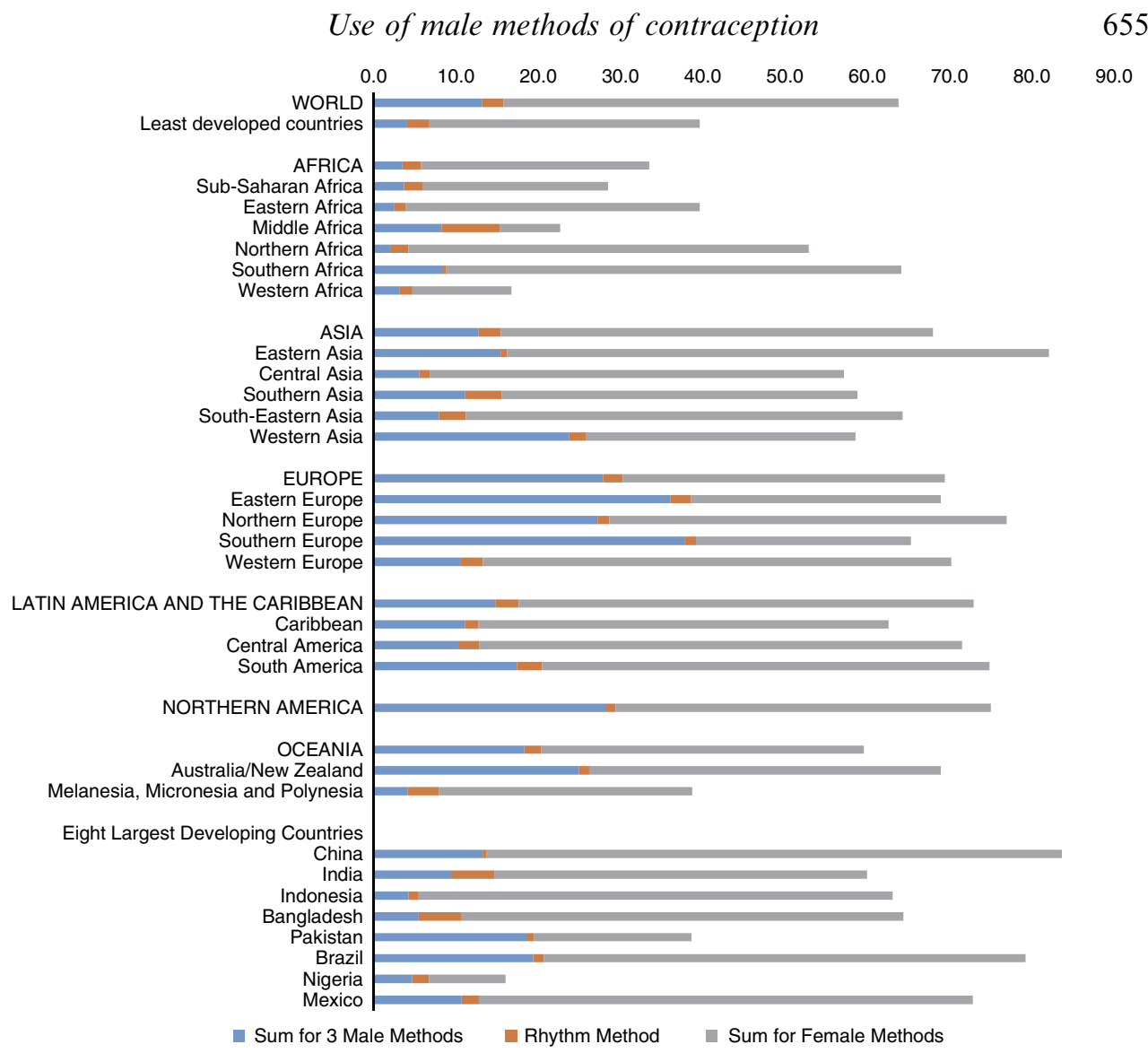

Fig. 2. Prevalence of male vs female contraceptive methods, by region.

using 80 DHS surveys with relevant variables. These include the male share in relation to total prevalence and the male total in relation to total prevalence, as well as the male gain in relation to the gain in total prevalence.

First, as Fig. 4a shows, the male share does not change as prevalence rises, indicating that additions to male use have occurred in addition to those for female use. Figure $4 \mathrm{~b}$ shows that total male prevalence and total prevalence correlate positively (a similar figure, not shown, gives a positive correlation between total female prevalence and total prevalence, while the correlation between male and female use is quite low, reflecting their independent contributions to total use across countries). Because the male share remains about the same regardless of whether prevalence is low or high, it tends to contradict the hypothesis that low prevalence means more reliance on rhythm and withdrawal. Turkey is a known historical exception, where withdrawal was the method of choice when prevalence was still low.

Of course there is a good deal of country variation around these observations. To demonstrate that, and to provide individual country information, Fig. 5 distributes all 80 countries jointly by total prevalence of use and by the sum of male method use. Each is separated at its median value $-8.6 \%$ for male use and $44.5 \%$ for prevalence - which 


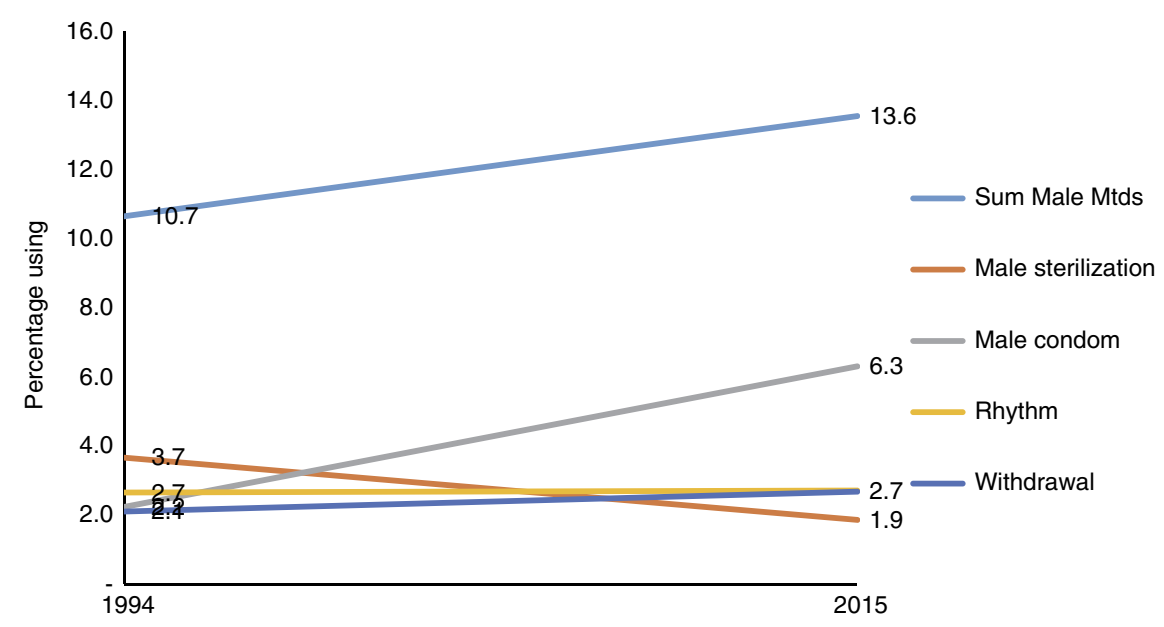

Fig. 3. Prevalence of male methods, 1994 and 2015. Values are weighted averages from 106 developing countries. At the lower right, the 2.7 pertains to both rhythm and withdrawal, which overlap.

puts 40 countries into each row and each column. Each country name is followed by the percentage using male methods. (The range of total use in the low-prevalence column is from $5.6 \%$ to $44.3 \%$ and in the high-prevalence column it is from $44.7 \%$ to $79.1 \%$.)

A marked diagonal pattern emerges in Fig. 5, with most countries in the low-low cell and in the high-high cell: 29 countries fall into each of those cells, making up 58 of the total of 80 . Only eleven countries fall into each of the other cells, for the other 22. Note that 25 of the 29 countries in the low-low cell are in sub-Saharan Africa. Thus greater male use and greater total use go together, with a strong regional component.

\section{Changes over time}

Because all of the above is cross-sectional, it is important to look at changes over time. Figure 6 compares the earliest survey with the latest survey, for a glimpse over time within individual countries. Fifty-seven individual countries had at least two DHS surveys in the past, with information on total prevalence and on each of the four male methods. The trends were examined in these countries, first to see whether the male share rose or fell as total prevalence rose. Figure 6a shows the lack of any relationship, confirming the cross-sectional result that as prevalence rose the male share stayed about the same. Then looking at total use rather than shares, Fig. $6 \mathrm{~b}$ shows that gains in total male use and gains in total use have historically moved together. Also, most countries fall into the upper right quadrant of the figure, confirming that most countries have in fact seen gains in both prevalence and male use.

National surveys of males only

A recent DHS report sets forth findings from 58 male-only surveys in eighteen countries, with extensive information on knowledge, attitudes, practices and fertility 
(a)
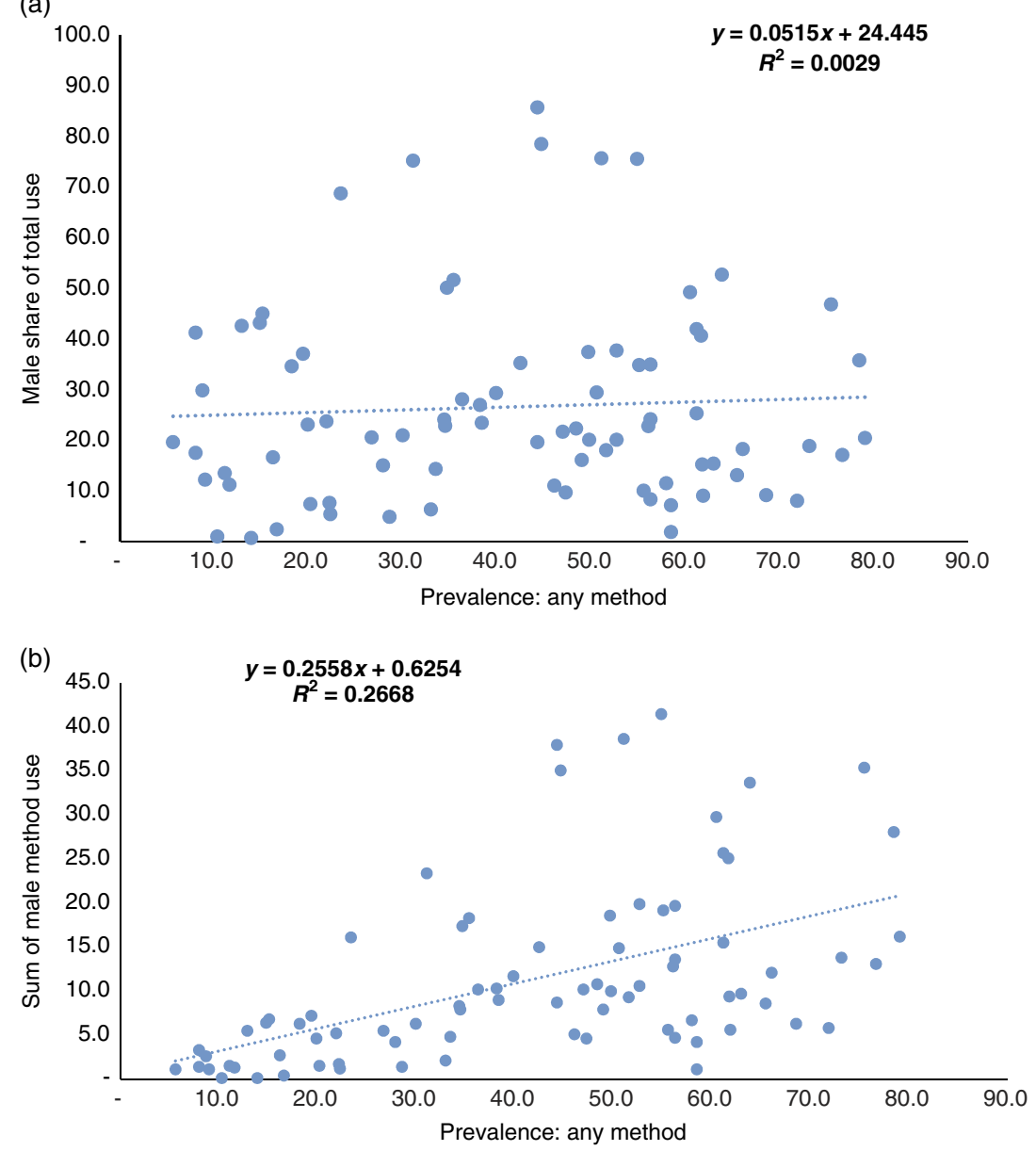

Fig. 4. Relation of the male share (a) and use of male methods (b) to use of any method.

(MacQuarrie et al., 2015). All surveys were national samples of males, most of them for all males aged 15-59 regardless of marital status. In every country, the men were more likely at last sex to use a modern than a traditional method. In most countries use was concentrated in only three or fewer methods (a finding that agrees with most national surveys of women). In ten of sixteen countries the condom accounted for over $50 \%$ of all contraceptive use.

While condom use is unusual among married men and is higher among the nevermarried and formerly married, both rhythm and withdrawal are higher among the currently married, as are the pill and injectable. That pattern is consistent across the countries. However, any contraceptive use at last sex is extremely variable, from $17 \%$ of men in the Demographic Republic of Congo to 63\% in Indonesia.

The percentage of men using male-controlled and co-operative methods of contraception at last sex is higher than the percentage whose partners used female-controlled 
Prevalence (\% Using Any Method)

\section{Sum of Male Methods (\%)}

$$
\text { LOW }
$$

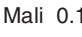

Ecuador 8.7
Sao Tome and Principe 9.0
Kyrgyzstan 10.2
Guatemala 10.3
Madagascar 11.7
Guyana 15.0
Cameroon 16.1
Maldives 17.4
Pakistan 18.3
Gabon 23.4
Congo Dem. Rep. 38.0

\section{High Prevalence}

Egypt 1.1

Zimbabwe 4.2

El Salvador 4.6

South Africa 4.7

Malawi 5.1

Uzbekistan 5.6

Indonesia 5.6

Dominican ReP. 5.8

Nicaragua 6.3

Kenya 6.7

Zambia 7.9

$\begin{array}{ll}\text { Thailand } 8.6 & \text { Colombia } 16.2 \\ \text { Rwanda } 9.3 & \text { Nepal 18.6 } \\ \text { Turkmenistan } 9.4 & \text { Philippines } 19.2 \\ \text { Morocco } 9.7 & \text { Cambodia } 19.7 \\ \text { Tunisia } 10.0 & \text { Trinidad and } \\ \text { Lesotho } 10.2 & \text { Tobago } 19.9 \\ \text { Mexico 10.6 } & \text { Sri Lanka 25.1 } \\ \text { Paraguay 10.9 } & \text { Jordan 25.7 } \\ \text { Kazakhstan } 12.1 & \text { Viet Nam 28.1 } \\ \text { Namibia } 12.8 & \text { Bolivia 29.8 } \\ \text { Brazil 13.1 } & \text { Turkey } 33.7 \\ \text { India 13.6 } & \text { Congo } 35.1 \\ \text { Honduras } 13.8 & \text { Peru 35.4 } \\ \text { Swaziland } 14.9 & \text { Azerbaijan } 38.7 \\ \text { Bangladesh } 15.5 & \text { Armenia } 41.5\end{array}$

Fig. 5. Countries classified by prevalence and sum of male methods. Cell values give percentage of couples using male methods. 
(a)

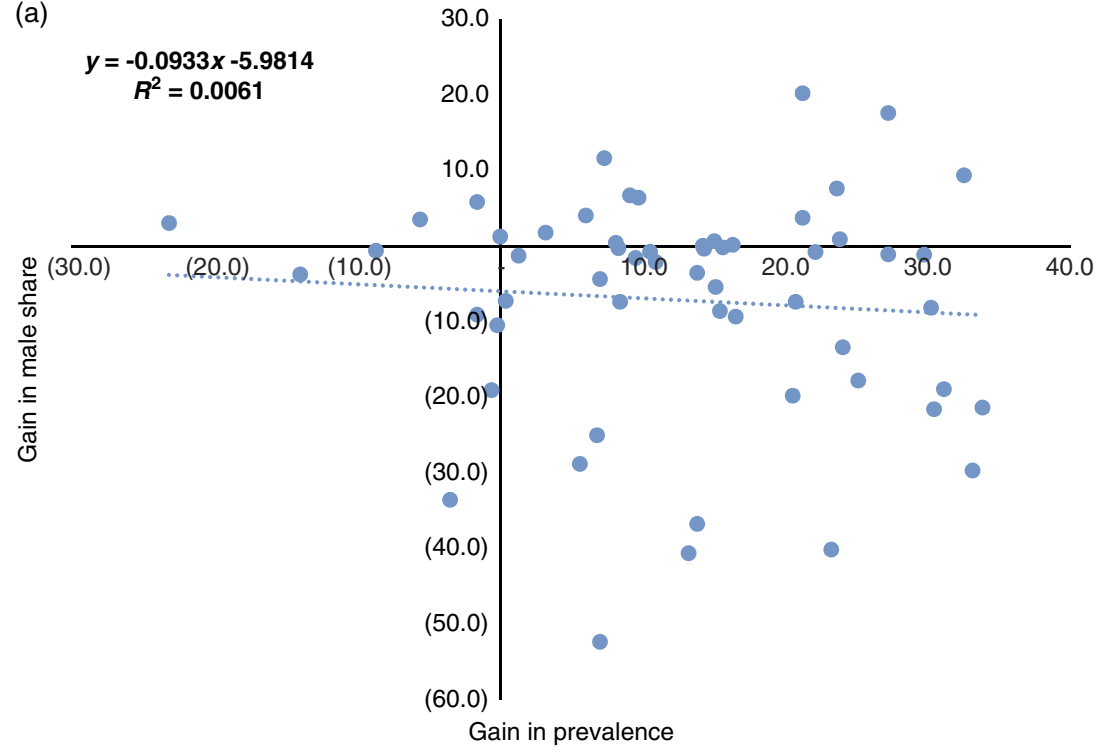

(b)

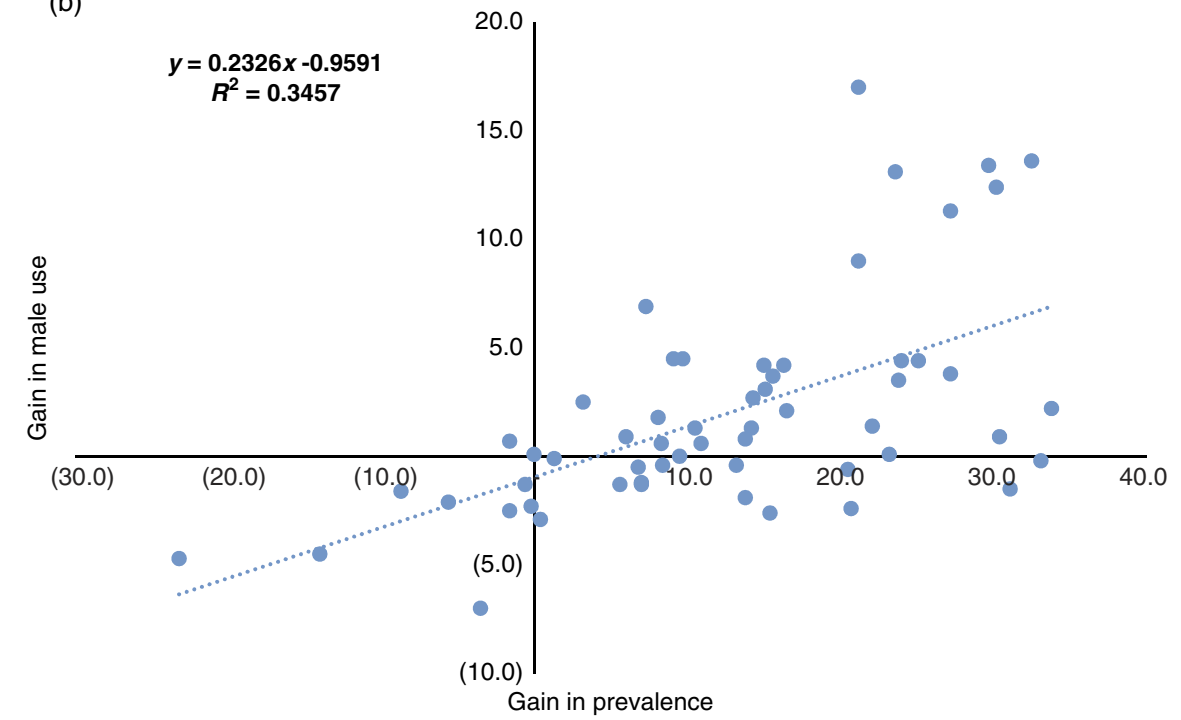

Fig. 6. Gain in male share (a) and gain in male use (b) related to gain in prevalence.

methods in eleven of seventeen countries, but the reverse in the other six countries. Countries agreed well concerning use according to the kind of partner. In all fourteen countries with data, fewer men used a method at last sex if they lived with their spouse or cohabiting partner, than if the partner was a commercial sex worker/casual acquaintance or a girlfriend/ financée. Regarding trends, only six of fourteen countries saw a significant increase in contraceptive use over time. However, the use of a modern method instead of a traditional 
one did increase in six other countries. Within the method mix the share due to condoms increased in most countries.

\section{Male vs female reporting of contraceptive use}

Do males report more contraceptive use than females in the same households do? The DHS surveys in 54 countries interviewed both, so the responses for each of the methods can be compared for women and men. First, about $2.3 \%$ of men report more condom use than women do, but women report more injectable use by about the same amount $(2.2 \%)$. By tiny margins $(0.1 \%)$ men report more withdrawal and rhythm use, while about $0.3 \%$ of women report more of the other methods. Overall, for 'any method', men report less use, by $1.4 \%$, than females do (data not shown). Within these averages a great deal of variation exists among countries and methods. For example, in Liberia men report 7.8 percentage points more condom use than women do $(8.2 \% \mathrm{vs}$ only $0.4 \%$ ). There is no easy explanation for such high variability, which is much greater in some countries. The best procedure is to focus on a single country and to look at all data from past surveys.

\section{Wealth quintile differences in male use and all contraceptive use}

The analyses above use national data; here, differences within countries according to wealth status are explored, based on the latest surveys in the 71 countries for which the DHS series provides wealth quintile data. The focus is on the use of any method and the share of use held by each of the male methods (Fig. 7a-e). Figure 7a, for any use, provides a benchmark, showing that total contraceptive use increases by wealth quintile in every region, with increases on average from $33.8 \%$ in the lowest quintile to $49.1 \%$ in the highest wealth quintile. Figures $7 \mathrm{~b}$ to $7 \mathrm{e}$ show the different patterns in the share of use for each of the four male methods by region and wealth quintile. Figure $7 \mathrm{~b}$ shows how the condom share of all use rises sharply at the upper wealth quintiles. Figure $7 \mathrm{c}$ shows a reduction in the share of use of withdrawal from the lowest to the highest wealth quintile. The trend is most pronounced in Western Asia and Eastern Europe; the exception is in Asia, where the share of withdrawal increases in higher wealth quintiles. Unlike the other male methods, the share of rhythm increases by wealth quintile on average and across all regions other than Latin America and the Caribbean, as shown in Fig. 6d. Use of male sterilization only registers with any significance in Asia and Latin America; also the pattern by quintile is opposite in the two regions. Use rises by wealth quintile in Latin America but falls in Asia (Fig. 7e).

The conclusion is that household wealth means quite different things in different regions and for different male methods. The clearest outcome is that in every region, the preference for condoms, the primary male method, increases systematically with increasing wealth, as does total use. At the same time, the actual level of condom use is low, rising only to about $7 \%$ of couples in the top quintile as an average over all 71 countries. Even the average share is only about $15 \%$ in the top quintile. (This might be higher if reported by males, or if use against HIV were included in some countries.) 
(a)

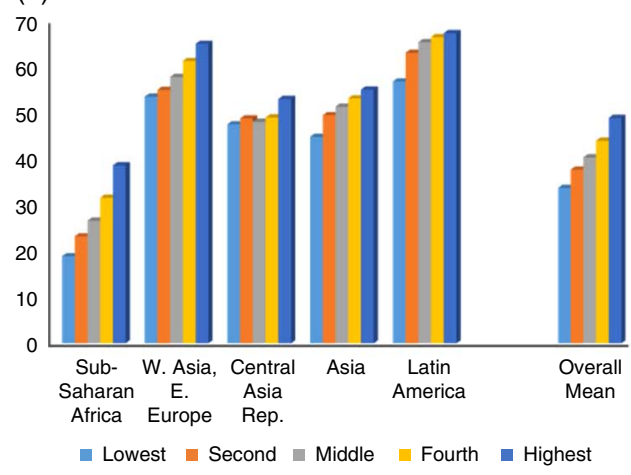

(c)

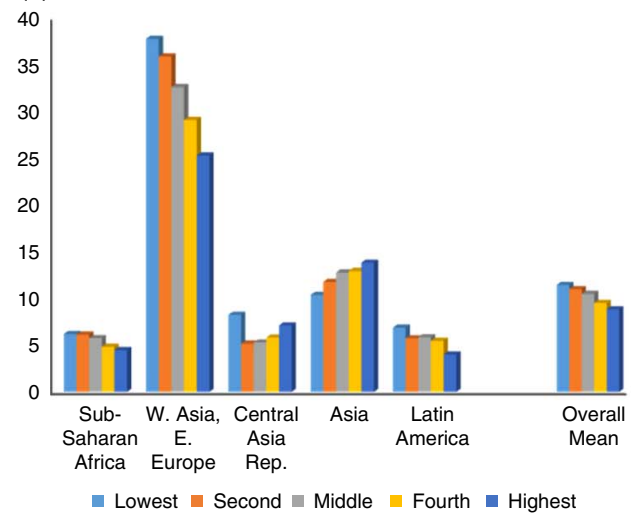

(e)

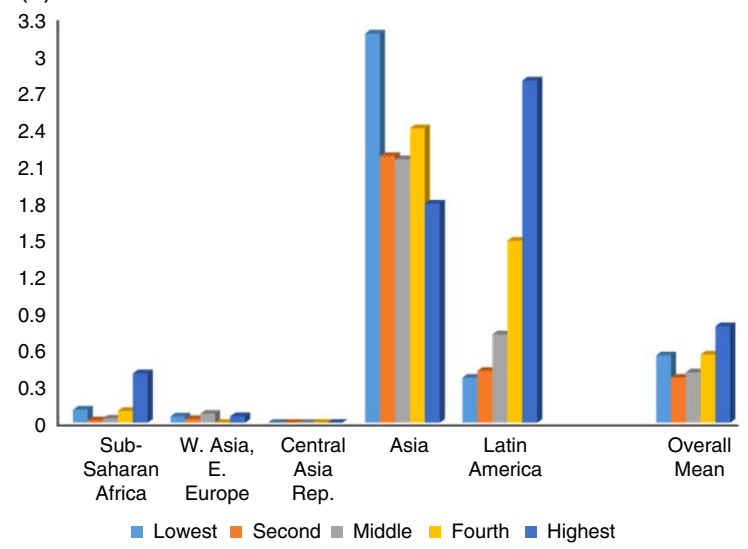

(b)

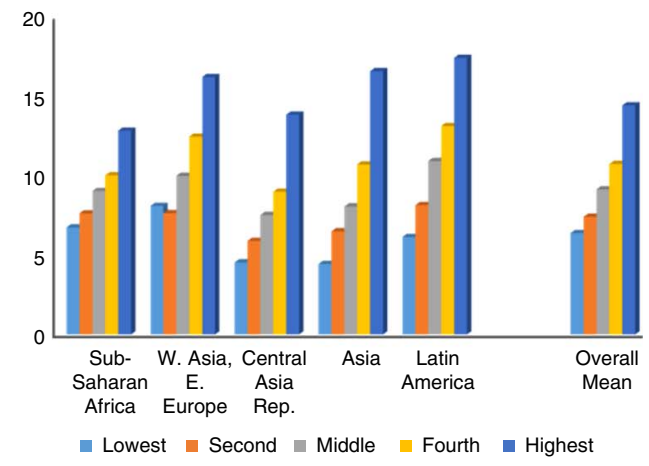

(d)

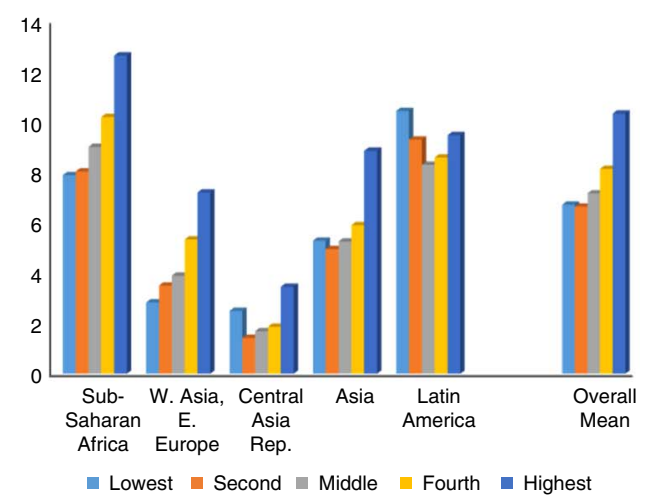




\section{Discussion}

The role of men as family planning users accounts globally for a quarter of all use and involves about one-seventh of all married couples, thus attention to both information and access to male methods is important for family planning programmes. That, however, breaks down separately by method. Male sterilization, far simpler and cheaper than female sterilization, is widely neglected in service provision and in public encouragement. Condoms are generally available but lack certain desirable qualities and are not popular for long-term use. The traditional methods of withdrawal and rhythm suffer from high failure rates, as do condoms, and they have been put somewhat in the shadow by the strong international stress on modern methods. Individual country programmes must form strategies that are particular to their own circumstances, in consideration of what can be accomplished in both public and private channels.

The stability of the finding that one-quarter of contraceptive use involves men attests to their overall importance, but equally, the great diversity in that figure and in the mix among the four methods reinforces the point that country programmes must adapt to local realities even while attempting to modify them. Each method has proved to be very significant in one region or country, with sharp differences by household wealth. Segmentation of programme strategies by wealth and by the potential of the private sector can ease burdens on government and donor resources.

The aim in this article has been to enlarge the available information on male contraceptive use, by method and in geographic detail, with time trends and wealth differentials. Regarding the future, the one-quarter proportion of all use related to males has on average been about the same during the rise of total use over time; male use and total use have risen in concert. Given these results it appears that use of male methods will continue to be relatively stable unless programmes commit to a greater emphasis on them, in the context of a broadened method mix.

\section{Acknowledgments}

Funding for this paper came from the Evidence Project through the United States Agency for International Development (USAID) under agreement No. AID-OAA-A-13-00087. The contents of this paper do not necessarily reflect the views of USAID or the United States Government. The authors are grateful to Ann Biddlecom for information and clarification of the UN data series.

\section{References}

Alkema, L., Kantorova, V., Menozzi, C. \& Biddlecom, A. (2013) National, regional and global rates and trends in contraceptive prevalence and unmet need for family planning between 1990 and 2015: a systematic and comprehensive analysis. The Lancet 381(9878), 1642-1652.

Bertrand, J. T., Sullivan, T. M., Knowles, E. A., Zeeshan, M. F. \& Shelton, J. D. (2014) Contraceptive method skew and shifts in method mix in low- and middle-income countries. International Perspectives in Sexual and Reproductive Health 40(3), 144-153.

Gallen, M. E., Liskin, L. \& Kak, N. (1986) Men: new focus for family planning programs. Population Reports Series J, No. 33, Nov-Dec 1986. 
Hardee, K., Croce-Galis, M. \& Gay, J. (2016) Men as Contraceptive Users: Evidence and Recommendations. The Evidence Project, Washington, DC. URL: http://evidenceproject. popcouncil.org/wp-content/uploads/2016/09/Men-as-FP-Users_September-2016.pdf

Hardee-Cleaveland, K. (1992) Use of male methods varies by region. Network 13(1), 10-12. URL: http://www.popline.org/node/321549

ICF International (2015) The DHS Program. Demographic and Health Surveys, Rockville, MD, USA.

Interagency Gender Working Group (IGWG) (2009) Engaging Men for Gender Equality and Improved Reproductive Health. IGWG, Washington, DC.

MacQuarrie, K. L. D., Edmeades, J., Steinhaus, M. \& Head, S. K. (2015) Men and contraception: trends in attitudes and use. DHS Analytical Studies No. 49. ICF International, Rockville, MD, USA.

Ross, J., Keesbury, J. \& Hardee, K. (2015) Trends in the contraceptive method mix in low- and middle-income countries: analysis using a new "average deviation" measure. Global Health: Science and Practice 3(1), 34-55.

Seiber, E. E., Bertrand, J. T. \& Sullivan, T. M. (2007) Changes in contraceptive method mix in developing countries. International Family Planning Perspectives 33(3), 117-123.

Sullivan, T. M., Bertrand, J. T., Rice, J. \& Shelton, J. D. (2006) Skewed contraceptive method mix: why it happens, why it matters. Journal of Biosocial Science 38(4), 501-521.

UN Population Division (2015a) Model-Based Estimates and Projections of Family Planning Indicators 2015. URL: www.un.org/en/development/desa/population/theme/family-planning/ cp_model.shtml; Modelled estimates and projections based on the country-specific data in World Contraceptive Use 2015. URL: www.un.org/en/development/desa/population/ publications/dataset/contraception/wcu2015.shtml.

UN Population Division (2015b) Trends in Contraceptive Use Worldwide 2015. ST/ESA/SER. A/349. URL: www.un.org/en/development/desa/population/publications/pdf/family/trends ContraceptiveUse2015Report.pdf.

UN Population Division (2015c) Estimates and Projections of the Number of Women aged 15-49 Married or in Union. URL: www.un.org/en/development/desa/population/theme/marriageunions/marriage_estimates.shtml 